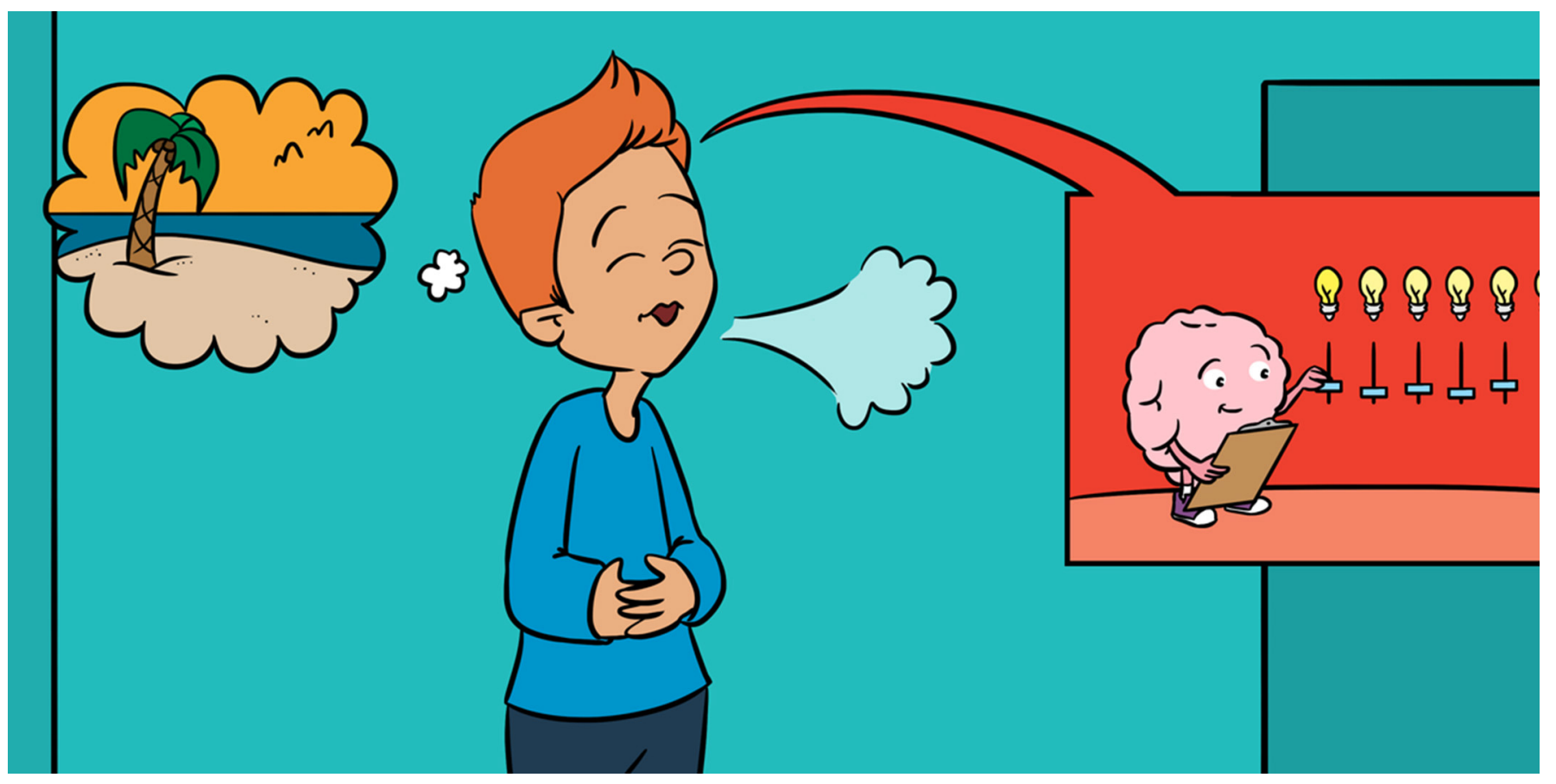

\title{
HOW MIND-BODY SKILLS CAN REDUCE PAIN AND IMPROVE COMFORT
}

\section{Samantha P. Bento, Amy E. Hale * and Rachael Coakley}

Department of Anesthesiology, Critical Care and Pain Medicine, Boston Children's Hospital, Harvard Medical School, Boston, MA, United States

YOUNG REVIEWERS:

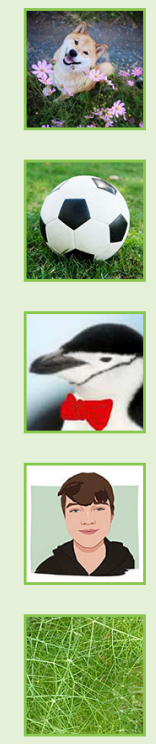

ABIGAIL

AGE: 12

KAIRAV

AGE: 14

KEN

AGE: 13

SETH

AGE: 12

TOBIAS

AGE: 14

Chronic pain is pain that lasts for more than 3 months. About one quarter of kids and teens have this type of pain. Chronic pain includes

\section{UNDERSTANDING CHRONIC PAIN}

Ever get a splinter in your finger? It hurts! You experience pain from a splinter because the nerves in your finger detect a problem, send a 


\section{CHRONIC PAIN}

Pain that lasts for 3 or more months. It is usually considered to be non-protective, meaning that it does not signal a danger or harm to the body.

\section{NERVOUS SYSTEM}

Nervous system includes your brain, spinal cord, and all of the nerves in your body. The nervous system's main job is to communicate information between your body and brain.

\section{PSYCHOLOGICAL}

\section{INTERVENTIONS}

Skills or techniques used to change a person's thoughts, feelings, or behavior to help them feel better. warning signal to your brain, and your brain says, "that splinter does not belong there, get it out!". The pain you feel from a splinter is protective. You feel it until you take out the splinter and your finger heals. That is how pain is supposed to work-you feel pain until the danger is gone and your body has healed.

Unlike a splinter, some pain can last for a long time. When pain lasts for more than 3 months it is called chronic pain. This is a pretty common problem, affecting 1 out of every 4 kids and teens [1]. Chronic pain can include problems like ongoing stomachaches, headaches, or joint, muscle, or nerve pain. Sometimes pain starts after an injury or illness, but chronic pain can also begin without any known cause. Most of the time, chronic pain is not protecting the body. Instead, we can think of chronic pain like a glitch in the nervous system. With chronic pain, the nervous system thinks it is protecting the body against a danger, but there is actually no harm happening. Chronic pain can be frustrating because it can interfere with many important day-to-day activities, like going to school, playing sports, hanging out with friends, doing hobbies, and even sleeping [2].

The idea of using psychologically based skills and strategies to treat chronic pain surprises many people because pain is usually believed to be just a physical problem. In truth, pain is actually a physical and emotional experience. Learning how pain is processed in the brain and nervous system makes it easier to understand why psychological strategies are an important part of the recovery.

\section{HOW DOES PSYCHOLOGY HELP WITH PAIN?}

Imagine that your nervous system is like the electrical wiring of a house. For people with chronic pain, it is like their system is overloaded with too much electrical current and it is constantly in a state of high alert trying to protect the body. To help people with chronic pain feel better, we have to re-set this overloaded system. When the nervous system's regular function is restored, chronic pain subsides.

Psychological interventions can help reduce the overload on the nervous system. There are two groups of skills that can be used for this purpose $[3,4]$. One group of skills-known as mind-body relaxation skills - work like dimmer swithes on a light. Decreasing or dimming down the overactive nervous system can reduce both pain and stress. The other group of skills that can help reduce nervous system overload are techniques that help to modify or change pain-related thoughts and behaviors. These skills work like on-off light switches to disrupt the flow of current through the overactive system. As a result, chronic pain cycles are broken, often leading to lasting improvements for kids with pain. Let us explore how dimmer techniques and light switch skills work to reduce the sensation of pain. 
Figure 1

Relaxation strategies can be used to help dial down the pain response. By Vinita Bharat, PhD from Fuzzy Synapse.
FIGHT-OR-FLIGHT RESPONSE

The body's natural response to feeling afraid. This includes faster heart rate, rapid or shallow breathing, tense muscles, and feelings of fear or dread. This response happens in any situation where the brain thinks something is dangerous.

\section{RELAXATION RESPONSE}

The body's natural response to feeling safe, calm, and comfortable. The relaxation response includes a slower heart rate, steady calm breathing, relaxed musles, and positive feelings.

\section{DIAPHRAGMATIC} BREATHING

Diaphragmatic breathing also known as "belly breathing" is a slow and structured way of breathing that uses a large abdominal muscle (the diaphragm) to deepen the breath. This brings more oxygen into the body, slows the heart rate, and relaxes muscles.

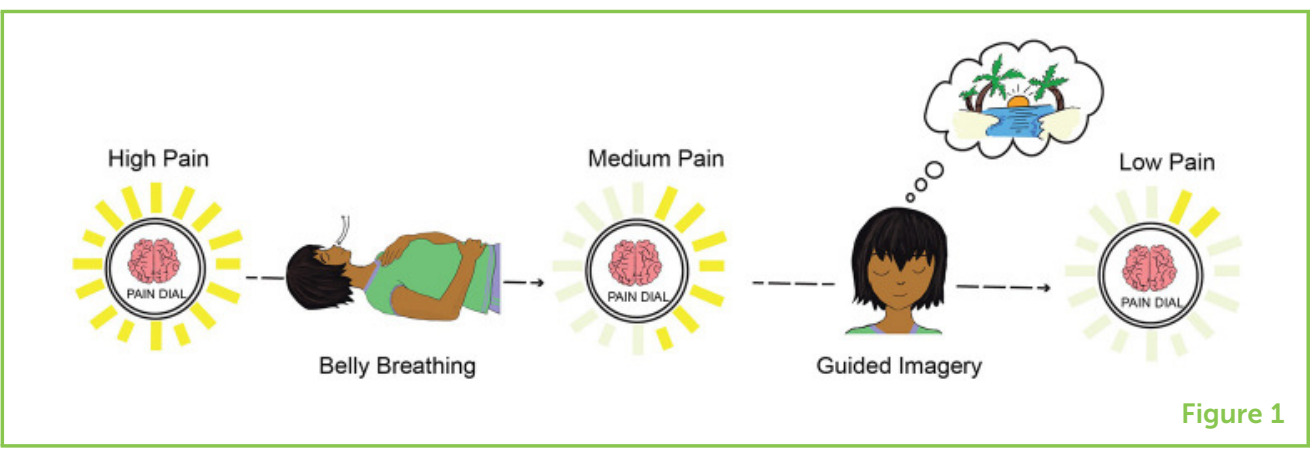

\section{DIMMERS: THE MIND-BODY RELAXATION RESPONSE}

Remember the splinter? To alert you to the problem when you get a splinter, the nerves in your finger send a warning message to your brain. One thing this message does is trigger the brain's danger-alert center, which is also called the fight-or-flight response. That response increases your heart rate and makes you feel a little (or a lot!) panicky so that you pay attention and protect your body. This response is amazingly helpful when there is a real danger to the body. Once the problem is addressed (for example, when you take out the splinter and grab yourself a Band-Aid), the nervous system automatically resets itself and resumes normal, relaxed functioning, and the pain goes away.

The problem is that chronic pain is not protective and does not usually signal a danger to the body. So, although the brain gets messages triggering the fight-or-flight response, there is no quick fix and no automatic reset. The result is an overactive nervous system that produces ongoing pain and panicky feelings.

Mind-body relaxation skills dial down the activation of the nervous system, shifting the body away from the danger alerts toward a sense of calm. This is called the relaxation response. You can create this effect by combining slow steady breathing with mental focus on a relaxing place, a positive experience, or even an object. Directing your breath and focus helps to dim or reduce the intensity of the nervous system's response. In effect, the nervous system stops paying as much attention to the false danger signals and re-sets to normal, calm functioning (Figure 1).

One of the most important relaxation skills is called diaphragmatic breathing or sometimes belly breathing. When chronic pain triggers a danger signal in the brain, the diaphragm-a muscle between the lungs and the stomach-pushes up against the lungs, causing rapid, shallow breathing. You can reverse this process by taking slow, rhythmic breaths into your belly, using your diaphragm to deepen the breaths. Breathing like this helps to trigger the relaxation response, a feeling of calm that comes from a slower heart rate, relaxed muscles, and reduced nervous system activity. 


\section{GUIDED IMAGERY}

A sensory filled guided story or meditation that uses the mind to create an "as-if" feeling in the body.

\section{MINDFULNESS}

A type of meditative practice that includes paying very close attention to something happening in the moment. A key part of mindfulness is letting go of judgements and just observing the present moment.
Guided imagery is another relaxation strategy that can be used like a dimmer to reduce nervous system activity and pain. In guided imagery, an interesting or relaxing sensory-rich story is used to draw attention away from pain and pain-related feelings of panic, fear, and sadness, and to focus the mind on pleasant experiences instead [e.g. www.thecomfortability.com/blogs/guided-exercises-relaxation]. Imagine walking on a beach with your family, feeling the cool, wet sand underneath your feet as the waves gently roll over your feet. You can hear the waves crashing and seagulls in the distance. Imagine breathing in the fresh, salty ocean air as the sun warms your skin. Feels relaxing, right? Guided imagery dials back or dims down the activation of the nervous system, creating a calming effect and helping to restore the body to a state of relaxation and normal function.

Mindfulness is another great relaxation skill that can be used to boost comfort and dim pain sensation. Mindfulness simply means paying close attention to something happening in the moment [5]. Choosing to focus the mind on a thought or experience in the moment means the mind has less opportunity to focus on pain or fear. Research shows that this helps the body to feel more relaxed and comfortable. Similar to guided imagery, mindfulness works best when you pay attention to senses such as taste, touch, sight and sound. For example, you can practice mindful eating, mindful walking, and mindful listening to music to help reduce the sensation of pain.

\section{LIGHT SWITCHES: BREAKING THE CYCLE OF CHRONIC PAIN BY CHANGING THOUGHTS AND BEHAVIORS}

When you get a splinter, what is the first thought that comes to your mind? It is probably, "This hurts so much!" or "I hate splinters!". It is normal to think these thoughts because no one ever likes a splinter. However, you may be surprised to learn that how you think about that splinter can change how much it will actually hurt. For example, if you think, "This is going to hurt so much when I pull it out", your brain keeps activating the danger-alert system, which makes you feel more pain. On the other hand, if you think, "This splinter is actually quite small and easy to remove", the danger alerts subside, the body relaxes, and you feel less pain.

In the case of chronic pain, in which symptoms can continue for months, it is easy to get stuck in a cycle of negative thoughts. For example, you might think, "This pain is ruining my life", or "I can not do anything because I hurt." Thoughts like these might be normal reactions to ongoing pain, but they can also create feelings of panic, sadness and worry. These negative thoughts and feelings keep the danger-alert system in high gear, so pain is more likely to persist or even worsen. Ongoing pain then leads to more negative thoughts, which lead to more pain, and on it goes. The negative thoughts and 
Figure 2

Psychological skills can be used to make important changes in people's routines to break negative pain cycles. By Katharin Shaw, PhD.

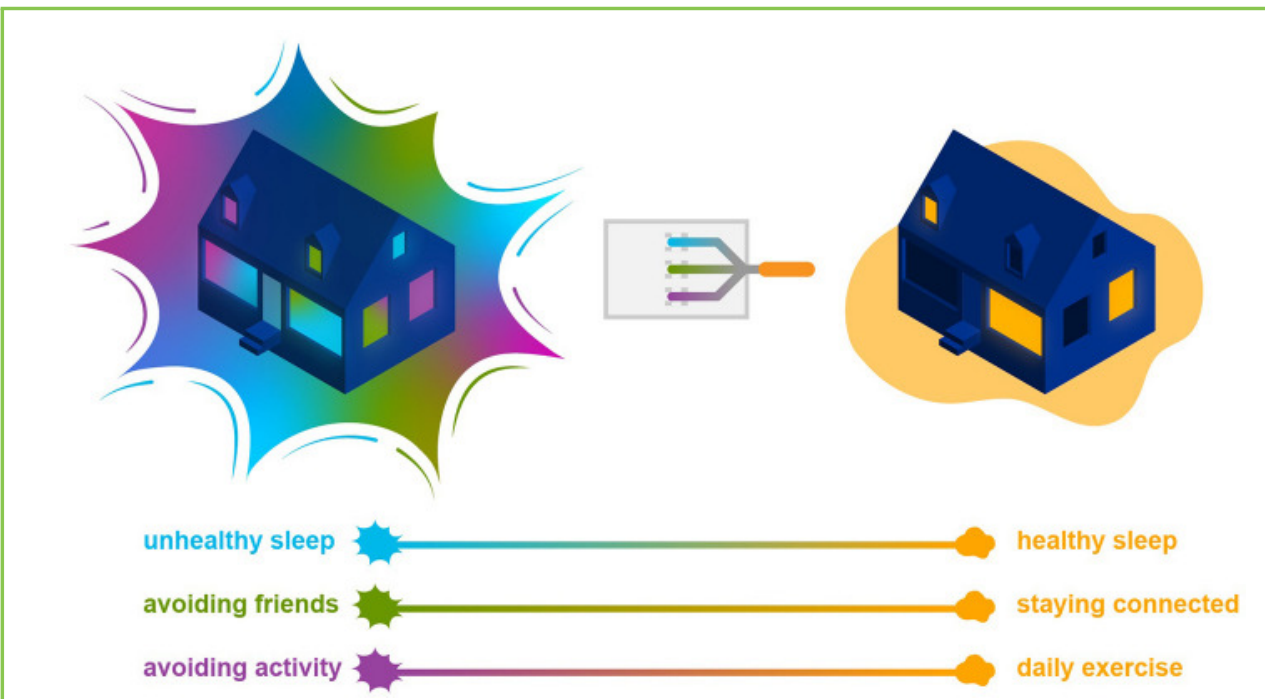

Figure 2

pain create a circuit that keeps the nervous system activated and keep pain front and center in your awareness.

Using skills from psychology, you can learn how to switch off these negative thought patterns. For example, instead of thinking, "This pain is ruining my life", you can learn and practice new thoughts like, "This is a tough day, but there are things I can do to help myself feel better". More balanced and less alarming thoughts like these do not set off the danger alerts in the brain. With the loop of negative thoughts and pain switched off, the brain and body can relax, and pain is reduced [6].

Psychological skills can also help to break or "switch off" the negative behavior cycles that worsen chronic pain [7]. For example, chronic pain can make you feel like you want to rest in bed all day. But resting in bed too much can interfere with sleep and make you feel more tired or weak. By resting too much, you might also miss out on the day-to-day activities that help your mind and body feel great. A negative cycle is created because more rest leads to doing less of what you enjoy, which leads to feeling stressed and unhappy which leads to more pain and frustration, which leads to more rest and so on. Psychological skills can teach people how to make important changes in their routines-for example, how to slowly and safely return to exercise-to switch off this negative behavior cycle (Figure 2).

\section{SUMMARY}

While chronic pain can be challenging to manage, most kids recover and get back to their busy lives. Psychology offers many science-proven skills and strategies that can help with chronic pain. Dimmer strategies are designed to trigger the relaxation response, 
turning off the glitchy danger-alert systems that can keep chronic pain going. Light switch strategies are used to disrupt the negative cycles of thoughts and behaviors that commonly occur when pain is ongoing for many months. Putting this all together, psychology helps kids learn the skills needed to essentially re-wire their nervous systems so that they can move beyond chronic pain and get back to living their lives!

\section{REFERENCES}

1. King, S., Chambers, C. T., Huguet, A., MacNevin, R. C., McGrath, P. J., Parker, L., et al. 2011. The epidemiology of chronic pain in children and adolescents revisited: a systematic review. Pain. 152:2729-38. doi: 10.1016/j.pain.2011.07.016

2. Palermo, T. M. 2000. Impact of recurrent and chronic pain on child and family daily functioning: a critical review of the literature. J. Dev. Behav. Pediatr. 21:58-69. doi: 10.1097/00004703-200002000-00007

3. Fisher, E., Heathcote, L., Palermo, T. M., Williams, A. C. C., Lau, J., and Eccleston, C. 2014. Systematic review and meta-analysis of psychological therapies for children with chronic pain. J. Pediatr. Psychol. 39:763-82. doi: 10.1093/jpepsy/jsu008

4. Coakley, R., and Wihak, T. 2017. Evidence-based psychological interventions for the management of pediatric chronic pain: new directions in research and clinical practice. Children. 4:9-26. doi: 10.3390/children4020009

5. Hayes, S.C., and Shenk, C. 2006. Operationalizing mindfulness without unnecessary attachments. Clin. Psychol. Sci. Pract. 11:249-54.

doi: 10.1093/clipsy.bph079

6. Law, E.F., Fisher, E., Fales, J., Noel, M., and Eccleston, C. 2014. Systematic review and meta-analysis: parent and family-based interventions for children and adolescents with chronic medical conditions. J. Pediatr. Psychol. 39:866-86. doi: 10.1093/jpepsy/jsu032

7. Harrison, L. E., Pate, J. W., Richardson, P. A., Ickmans, K., Wicksell, R. K., and Simona, L. E. 2019. Best-evidence for the rehabilitation of chronic pain part 1: pediatric pain. J. Clin. Med. 8:1267-84. doi: 10.3390/jcm8091267

SUBMITTED: 31 March 2021; ACCEPTED: 16 December 2021; PUBLISHED ONLINE: 17 January 2022.

EDITOR: Jie Zheng, Boston Children's Hospital, United States

\section{SCIENCE MENTOR: Elsy Ngwa}

CITATION: Bento SP, Hale AE and Coakley R (2022) How Mind-Body Skills Can Reduce Pain and Improve Comfort. Front. Young Minds 9:682687. doi: 10.3389/ frym.2021.682687

CONFLICT OF INTEREST: The authors declare that the research was conducted in the absence of any commercial or financial relationships that could be construed as a potential conflict of interest. 

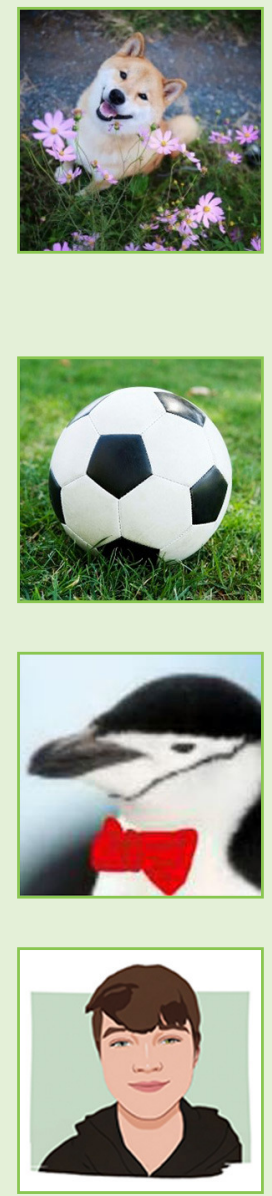

\section{SETH, AGE: 12}

I am a 7th grade student who enjoys science, tennis, golf and animals. My family, I have a mom and dad and two older brothers, fosters dogs, and cats until they find their forever homes. It is a lot of fun. We also have our own dog and two cats.

TOBIAS, AGE: 14

Tobias is an avid turtle-lover. He enjoys reading, old music, and scarves. While he dislikes horror, he enjoys creating creepy things very much.

\section{AUTHORS}

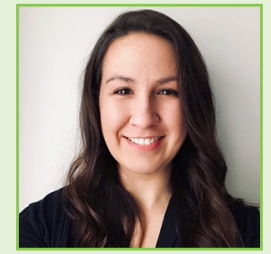

\section{SAMANTHA P. BENTO}

I am a psychologist at Boston Children's Hospital where I specialize in working with children, adolescents, and young adults with all types of chronic pain conditions. One of my areas of focus is helping patients manage acute and chronic perioperative 

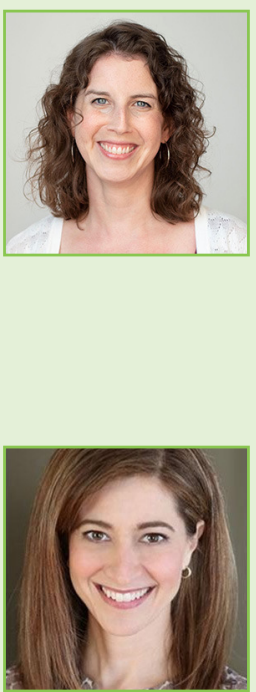

pain, or pain that is present before or after surgery. Another area of interest is developing interventions to help manage cancer-related pain. My research takes a mind-body approach to explore interactions between biological processes (immune function and stress responses), psychological factors, and pain.

\section{AMY E. HALE}

I am a psychologist at Boston Children's Hospital where I help kids and teenagers with pain and gastrointestinal problems with poop, vomit, and feeding. I help lead the Comfort Ability Program, where we teach kids and families science-backed mind-body skills for pain management. I do research about how to help kids and teens recover from pain and other physical symptoms using mind-body strategies, and teach teams from other hospitals how to share these skills too. *amy.haleachildrens.harvard.edu

\section{RACHAEL COAKLEY}

I am a pediatric psychologist at Boston Children's Hospital and I specialize in pain management. For over 10 years I have been researching and teaching about the way pain is processed in our brains and how we can use psychological skills and strategies to reduce pain and improve comfort. I am the founder and director of the Comfort Ability Program, a set of workshops designed to teach kids, teens, and parents the psychological skills needed to reduce pain and get back to life. You can find Comfort Ability workshops across the US, Canada, and Australia. To find a workshop or learn more about chronic pain, check out our website: www.thecomfortability.com 